\title{
Salicylate Induces Tinnitus through Activation of Cochlear NMDA Receptors
}

\author{
Matthieu J. Guitton, ${ }^{1}$ Jean Caston, ${ }^{2}$ Jérôme Ruel, ${ }^{1}$ Randolph M. Johnson, ${ }^{3}$ Rémy Pujol, ${ }^{1}$ and Jean-Luc Puel ${ }^{1}$ \\ ${ }^{1}$ Institut National de la Santé et de la Recherche Médicale UR-254, Laboratoire de Neurobiologie de l'Audition-Plasticité Synaptique, Faculté de Médecine, \\ Université de Montpellier 1, 34090 Montpellier, France, ${ }^{2}$ Unité Propre de Recherche et de l'Enseignement Supérieur 1780, Laboratoire de Neurobiologie de \\ l'Apprentissage, Université de Rouen, 76821 Mont-Saint-Aignan, France, and ${ }^{3}$ DURECT Corporation, Cupertino, California 95014
}

\begin{abstract}
Salicylate, the active component of aspirin, is known to induce tinnitus. However, the site and the mechanism of generation of tinnitus induced by salicylate remains unclear. Here, we developed a behavioral procedure to measure tinnitus in rats. The behavioral model was based on an active avoidance paradigm in which rats had to display a motor task (i.e., to jump on a climbing pole when hearing a sound). Giving salicylate led to a decrease in the percentage of correct responses (score) and a drastic increase in the number of false positive responses (i.e., animals execute the motor task during a silent period). Presentation of the sound at a constant perceptive level prevents decrease of the score, leading to the proposal that score is related to hearing performance. In contrast, the increase of false positive responses remained unchanged. In fact, animals behaved as if they hear a sound, indicating that they are experiencing tinnitus. Mefenamate in place of salicylate also increased the number of false positive responses, suggesting that salicylate-induced tinnitus is related to an inhibition of cyclooxygenase. One physiological basis of salicylate ototoxicity is likely to originate from altered arachidonic acid metabolism. Because arachidonic acid potentiates NMDA receptor currents, we tested the involvement of cochlear NMDA receptors in the occurrence of tinnitus. Application of NMDA antagonists into the perilymphatic fluids of the cochlea blocked the increase in polejumping behavior induced by salicylate, suggesting that salicylate induces tinnitus through activation of cochlear NMDA receptors.
\end{abstract}

Key words: tinnitus; NMDA receptor; local therapy; cyclooxygenase pathway; behavioral model; salicylate

\section{Introduction}

Approximately 20 million people in the United States of America experience tinnitus (ringing in the ears), and probably two million of them suffer from tinnitus that interferes substantially with their daily occupation and activities. It is well known for at least a century that a large dose of aspirin (acetylsalicylic acid) produces hearing loss and tinnitus that recover after stopping treatment (Sée, 1877). These effects have been attributed to the salicylate ion, the active component of aspirin (for review, see Cazals, 2000). Salicylate competes with the contribution of cytoplasmic chloride to nonlinear capacitance of sensory outer hair cells (OHCs) (Kakehata and Santos-Sacchi, 1996; Zheng et al., 2000; Oliver et al., 2001; Zhang et al., 2001), providing an explanation for hearing loss induced by aspirin. However, the site and the mechanism of generation of the tinnitus induced by salicylate still remains unclear.

Electrophysiological studies reported that injection of salicylate increased spontaneous activity of single units of the auditory nerve (Evans et al., 1981; Evans and Borerwe, 1982; Stypulkowski, 1990) and modified the average spectrum activity recorded from the round window, which is a gross measure of spontaneous activity of the auditory nerve (Schreiner and Snyder, 1987; Martin et al., 1993; Cazals et al., 1998). The characteristics of these

Received Aug. 5, 2002; revised Feb. 10, 2003; accepted Feb. 20, 2003.

J.R. has a fellowship from Caisse Nationale d'Assurance Maladie. We thank Drs. Tangui Maurice, Sanford C. Bledsoe Jr., Colleen Garbe Le Prell, Jing Wang, and Cécile Nicolas-Puel for helpful comments on this work. We thank David Sarruf and Jean-Louis Pasquier for editing this manuscript.

Correspondence should be addressed to Jean-Luc Puel, Institut National de la Santé et de la Recherche Médicale UR-254, 71 rue de Navacelles, 34090 Montpellier, France. E-mail: puel@montp.inserm.fr.

Copyright $\odot 2003$ Society for Neuroscience $\quad 0270-6474 / 03 / 233944-09 \$ 15.00 / 0$ changes appear to be similar to the characteristics of salicylateinduced tinnitus in animals (Cazals et al., 1998). This suggests that, at least in part, tinnitus induced by salicylate is associated with dysfunction of the auditory nerve.

Salicylate has been shown to inhibit cyclooxygenase activity (Vane, 1971; Mitchell et al., 1993; Vane and Botting, 1998). Cyclooxygenase 1 (COX-1) and its inducible isoform COX-2 convert arachidonic acid to prostaglandin H2 (Thiemermann, 1991; Vane et al., 1998). Evidence demonstrates that arachidonic acid potentiates NMDA receptor currents (Miller et al., 1992; Horimoto et al., 1996; Casado and Ascher, 1998). In the cochlea, fast excitatory synaptic neurotransmission is mediated by AMPA receptors (Ruel et al., 1999, 2000; Glowatzki and Fuchs, 2002). However, NMDA receptors have been reported to be involved in synaptic repair after excitotoxicity (d'Aldin et al., 1997), and NMDA antagonists protect sensory hair cells from aminoglycoside ototoxicity (Basile et al., 1996) and prevent excitotoxicity induced by cochlear ischemia and acoustic trauma (Puel et al., 1994; Duan et al., 2000).

The purpose of the present study was to determine whether cochlear NMDA receptors are involved in the generation of tinnitus induced by salicylate. Tinnitus was assessed with an active avoidance paradigm. Animals had to display a motor task (i.e., to jump on a climbing pole) when hearing a sound matching salicylate-induced tinnitus in rats (Jastreboff and Sasaki, 1994). Salicylate treatment drastically increased the number of false positive responses. Mefenamate also increased false positives, leading to the proposal that salicylate-induced false positives involve cyclooxygenase inhibition. Local application of NMDA antagonists into perilymphatic fluids blocked the occurrence of false posi- 
tives. The interpretation that false positives reflect the occurrence of tinnitus and that tinnitus is mediated by cochlear NMDA receptors is further discussed.

\section{Materials and Methods}

The care and use of animals followed the animal welfare guidelines of the Institut National de la Santé et de la Recherche Médicale (INSERM) and was under the approval of the Ministère Français de l'Agriculture et de la Forêt. All efforts were made to minimize the number of animals used and their suffering. A total of 112 female adult Long-Evans rats weighting between 120 and $180 \mathrm{gm}$ were used for the experiments. Animals were housed individually in a temperature-controlled room on a constant 12 $\mathrm{hr}$ light/dark cycle. All behavioral testing was conducted during the activity period of animals (dark phase) approximately at the same time each day. Ad libitum food and tap water were available in the home cage throughout the experiments.

\section{Experimental protocol}

Animals were trained to respond to a conditioned stimulus. Animals were conditioned with a $10 \mathrm{kHz}$ tone, except 10 animals conditioned with a $4 \mathrm{kHz}$ tone that served as an additional control. Conditioned animals were then tested daily for 9 consecutive days. Two measurements were performed: the number of correct responses to sound (score) and the number of responses without sound (false positives). Then, animals received daily intraperitoneal injections of saline alone $(n=10)$ or containing $300 \mathrm{mg} / \mathrm{kg}$ sodium salicylate ( $n=10$; Sigma, St. Louis, MO) or 35 $\mathrm{mg} / \mathrm{kg}$ mefenamate $(n=10$; Sigma) for $4 \mathrm{~d}$. Injections were performed 2 $\mathrm{hr}$ before behavioral measurements. Compound action potential (CAP) $(n=6)$ of the auditory nerve and distortion product otoacoustic emissions (DPOAEs) $(n=6)$ audiograms were performed under slight anesthesia [3 mg/kg Rompun (Bayer Pharma, Puteaux, France) and $40 \mathrm{mg} / \mathrm{kg}$ Zoletil (Virbac, Carros, France), intraperitoneally]. To avoid changes attributable to hearing loss induced by salicylate, the intensity of sound eliciting behavioral responses was adjusted as a function of CAP threshold shift $(n=10)$. Involvement of cochlear NMDA receptors in behavioral responses (score and false positive responses) was investigated by applying drugs into the fluid of the cochlea via Gelfoam placed on the round window membrane. Four groups of salicylate-treated animals were used. The control group received Gelfoam bathed with control artificial perilymph $(n=10)$, and the three experimental groups received Gelfoam bathed with $10 \mu \mathrm{M}(+)$-5-methyl-10,11-dihydro-5H-dibenzo [a,d] cyclohepten-5,10-imine maleate (MK-801) $(n=10$; dizocilpin; Tocris Cookson, Ballwin, MO), $50 \mu \mathrm{M}$ 7-chlorokynurenate (7-CK) $(n=$ 10; Sigma), or $50 \mu \mathrm{M}$ gacyclidine ( $n=10$; a generous gift from Dr. J.-M. Kamenka, INSERM, Montpellier, France). An additional group treated with mefenamate received $50 \mu \mathrm{M} 7$-chlorokynurenate $(n=10)$.

\section{Behavioral procedure}

Animals were trained to perform an active avoidance task. Tests were performed in a conditioning box with an electrical floor and a climbing pole. The conditioning paradigm consisted of dispatched sessions of 10 trials per session (Fig. 1).

Conditioning to the task. During conditioning, the sessions lasted $15-20 \mathrm{~min}$. The conditioning stimulus was a $50 \mathrm{~dB}$ sound pressure level (SPL) pure tone with a frequency of $10 \mathrm{kHz}$ of $3 \mathrm{sec}$ duration, and the unconditioned stimulus was a $3.7 \mathrm{~mA}$ electrical footshock presented for $30 \mathrm{sec}$ at most. Time between conditioned stimulus and unconditioned stimulus was $1 \mathrm{sec}$. Electrical shocks were stopped by the experimenter when the animal correctly climbed. Intertrial intervals were at least 1 min. The score was the level of performance assessed by the number of times the rat correctly climbed in response to sound. Animals were considered to be conditioned when the level of performance reached at least $80 \%$ in three consecutive sessions.

Behavioral testing. When conditioned (i.e., score $\geq 80 \%$ in three consecutive sessions), animals were included into the experiments. The behavioral testing protocol consisted of a daily measurement of both the score (correct responses to sound) and false positive responses. False positive responses were the number of climbings during intertrial periods (i.e., responses during silent periods). If animals stayed on the pole

\section{Conditioning}

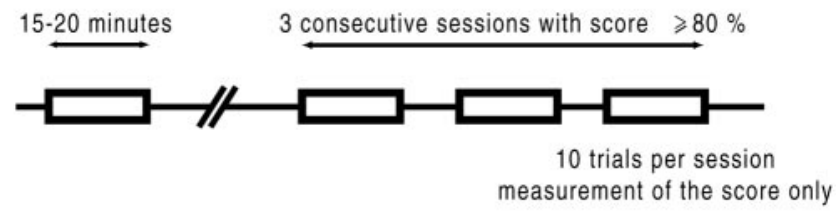

\section{Testing}

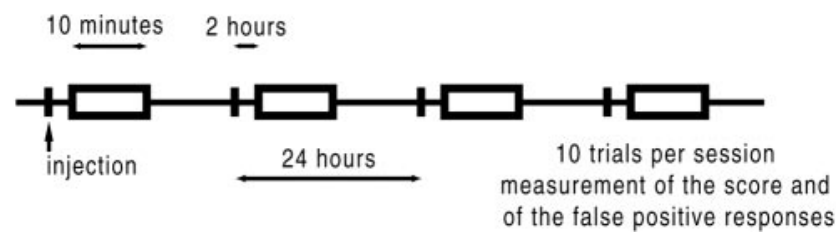

Figure 1. Schematic representation of the behavioral protocol. Animals were conditioned to jump on a climbing pole in response to a sound stimulation. Each session included 10 trials. The conditioning procedure requires up to seven sessions lasting $15-20$ min (i.e., 2 or $3 \mathrm{~d}$ ). When conditioned (criterion, 3 consecutive sessions with a score $\geq 80 \%$ ), animals were included in the experiments. The behavioral testing protocol $(9 \mathrm{~d})$ consisted of a daily measurement of the correct responses to sound (score) and climbings during intertrial periods (false positives or responses during silent periods) in the same $10 \mathrm{~min}$ session. Saline, salicylate, or mefenamate were injected daily $2 \mathrm{hr}$ before the testing session.

$>10 \mathrm{sec}$, they were put down on the floor. Trials were randomized, and electrical footshocks were only presented if the animal did not climb in response to sound. Whatever the score and the false positive responses, each session included 10 trials and lasted $10 \mathrm{~min}$. Both score and false positive responses were measured in the same session.

\section{Surgical procedures}

Conditioned animals were anesthetized intraperitoneally with $0.3 \mathrm{ml} / \mathrm{kg}$ sodium pentobarbital at 6\% (Sanofi, Montpellier, France) and operated under aseptic conditions. The right bulla was opened through a posterior auricular surgical procedure (dorsal approach) to expose the cochlea.

Chronic electrode implantation. A recording electrode was placed on the bony edge of the round window. A reference electrode was placed in the neck muscles. The reference electrode and the round window electrode were then soldered to a plug fixed on the skull. The bulla was closed with dental cement, and the surgical wound was sutured. Animals were allow to recover for $2 \mathrm{~d}$ before the beginning of electrophysiological recordings and behavioral testing.

Local drug delivery. Surgery to place Gelfoam on the round window of both ears was done immediately after the first behavioral measurement (day 0). After exposition of the cochlea through a dorsal approach, Gelfoam (Gelita tampon; B. Braun Medical, Melsungen, Germany) bathed with $2.5 \mu \mathrm{l}$ of artificial perilymph containing or not NMDA antagonists was placed on the round window. The artificial perilymph solution had the following composition (in mM): $140 \mathrm{NaCl}, 4 \mathrm{KCl}, 2 \mathrm{CaCl}_{2}, 2 \mathrm{MgCl}_{2}$, 10 HEPES, and 10 glucose, $\mathrm{pH} 7.4$ (osmolarity, $301 \pm 3.7 \mathrm{mOsm} / \mathrm{kg}$ $\mathrm{H}_{2} \mathrm{O}$ ). The NMDA antagonist MK- 801 was used at a concentration of 10 $\mu \mathrm{M}$, and 7-chlorokynurenate and gacyclidine were used at a concentration of $50 \mu \mathrm{M}$. Drugs were dissolved in DMSO to make stock solutions and stored at $-4^{\circ} \mathrm{C}$ until used. Before each experiment, drugs were diluted in artificial perilymph to reach the tested concentration. The amount of DMSO was adjusted to maintain a $0.1 \%$ concentration for each drug dilution. When applied onto the round window, Gelfoam containing such concentrations of NMDA antagonists did not induce nystagmus or dizziness, suggesting a lack of effect on the vestibular function.

Evaluation of auditory function during salicylate treatment CAP audiograms. Animals were chronically implanted with an electrode on the round window. CAPs of the auditory nerve were elicited with tone 
burst with a $1 \mathrm{msec}$ rise-fall time and a $9 \mathrm{msec}$ total duration generated by an arbitrary function generator (type 9100R; LeCroy Corporation, Chestnut Ridge, NY). The signals were passed through a programmable attenuator and presented to the ear in free field via a JBL 075 earphone (JBL, Northridge, CA). Ten frequencies were tested $(2,4,6,8,10,12,16$, 20,26 , and $32 \mathrm{kHz}$ ), with increasing levels of $5 \mathrm{~dB}$ from 0 to $100 \mathrm{~dB}$ SPL. The rate of presentation was 10 bursts per second. Cochlear responses were amplified (gain of 2000) by a differential amplifier (Grass P511K; Astro-Med, West Warwick, RI), and the signals were filtered (bandpass, $100 \mathrm{~Hz}$ to $3 \mathrm{kHz}$ ) and averaged (256 tests) on a Pentium computer (Dell Dimension; Dell Computer Company, Austin, TX). The sampling rate of the analog-to-digital converter was $50 \mathrm{kHz}$, with a dynamic range of 12 bits and 1024 samples per record. CAPs were measured peak-to-peak between the first negative (N1) and the following positive value (P1). The thresholds were defined as the level of decibels SPL needed to elicit a measurable response ranging from 2 to $5 \mu \mathrm{V}$.

DPOAEs audiogram. When two acoustic pure-tone stimuli (i.e., primary tones) are presented to a healthy ear, nonlinear interactions along the basilar membrane lead to the generation of DPOAEs (i.e., $f_{2}-f_{1}, 2 f_{1}-f_{2}$, $3 f_{1}-2 f_{2} \ldots$, where $f_{1}$ and $f_{2}$ are the primary tone frequencies). The cubic difference tones $\left(2 f_{1}-f_{2}\right)$ are thought to be generated from a reverse traveling wave originating at the cochlear site where the interaction between the two primaries is the strongest, i.e., the site tuned to $f_{2}$ (Puel et al., 1995). This reverse wave is propagated backward through the middle ear, where it can be acoustically detected by a sensitive microphone.

DPOAEs were elicited $\left(f_{2} / f_{1}=1.2\right.$; intensity of $f_{1}$ and $f_{2}=60 \mathrm{~dB} \mathrm{SPL}$ reference $2.10^{-5} \mathrm{~Pa} ; f_{2}$ ranging from $4-20 \mathrm{kHz}$; four points per octave) and recorded with a three-channel acoustic probe (ER-10C; Etymotic Research, Elk Grove Village, IL) tightly inserted in the external ear canal of the animal. The collected acoustic signal was amplified by a preamplificator (ER-10C DPOAE probe driver preamp; Etymotic Research), and data were analyzed with the software CUB ${ }^{\mathrm{e}}$ DIS (Mimosa Acoustics, Mountainside, NJ). The level of background noise never exceeded -15 / $-10 \mathrm{~dB}$ SPL.

\section{Statistical analysis}

In each behavioral experiment, comparisons of the relevant parameters were made according to a two-way (group $\times$ time, with repeated measures on the last factor) ANOVA to test the measurement effect (group effect), the time effect, and the group $\times$ time interactions. The ANOVA was followed by post hoc comparisons (Tukey's test). Statistical analysis of CAP and DPOAE measurements were made according to a one-way ANOVA, followed by Dunnett's test. All results were presented as mean \pm SEM.

\section{Results}

The animals needed four to seven sessions of 10 trials to be conditioned, and all responded correctly to the conditioning stimulus (sound) during the last three training sessions with scores of at least $80 \%$. The entire conditioning procedure requires 2 or $3 \mathrm{~d}$. Score and false positive responses were then measured on 9 consecutive days, and the animals received daily intraperitoneal injections for $4 \mathrm{~d}$ (from day 1 to day 4 ).

\section{Score and false positive response measurement}

Control animals received intraperitoneal injections of saline solution. This group of animals showed no significant change in either score (Fig. $2 A$ ) or false positive responses (Fig. $2 B$ ). In contrast, the animals treated with $300 \mathrm{mg} / \mathrm{kg}$ salicylate for $4 \mathrm{~d}$ presented modifications of score (Fig. $2 \mathrm{~A}$ ) and false positive responses (Fig. $2 B$ ). Before salicylate treatment (day 0 ), the mean score was $91.0 \pm 2.76 \%$. This score decreased to reach a plateau on the third $(p<0.05)$ and fourth $(p<0.05)$ days of treatment $(78.0 \pm 2.49$ and $79.0 \pm 1.79 \%$ at days 3 and 4 , respectively). A recovery to the pretreatment value was observed $1 \mathrm{~d}$ after salicylate injections stopped $(91.0 \pm 2.77 \%$ at day 5$)$ and remained in the normal range until the end of the experiment $(87.0 \pm 2.6 \%$ at

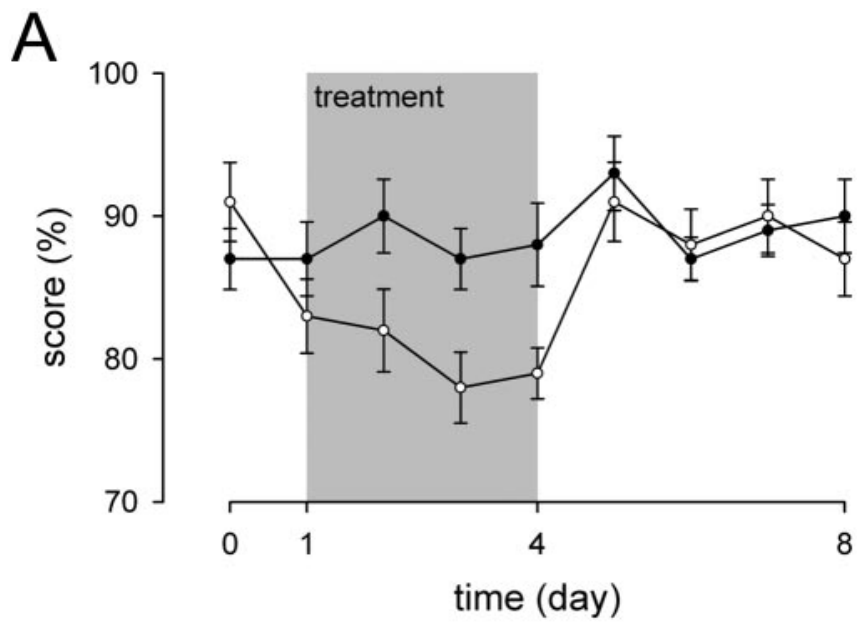

$\mathrm{B}$

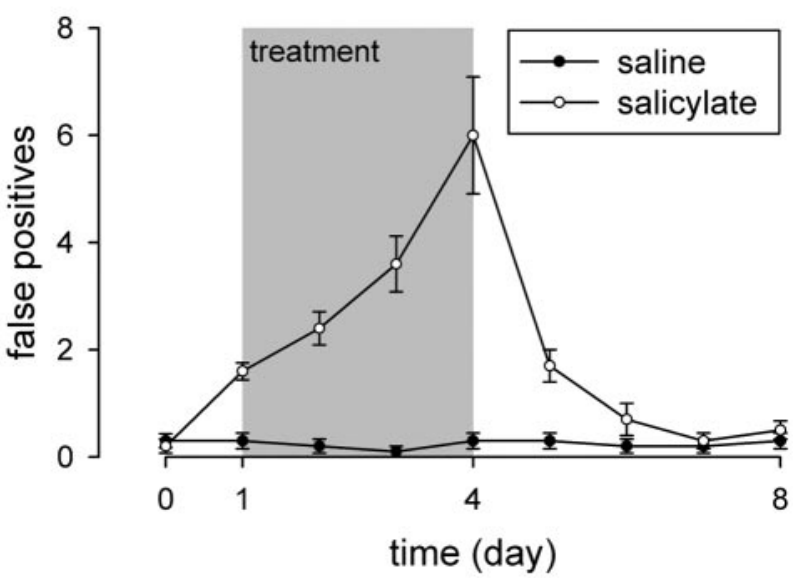

Figure 2. Measurement of the score and false positive responses in salicylate-treated animals. Animals were conditioned to display a motor task (i.e., to jump on a climbing pole) in response to the presentation of a sound ( $10 \mathrm{kHz}, 3 \mathrm{sec}$ duration). A represents the percentage of correct responses to sound (score) measured before (day 0 ), during (days 1-4; gray area), and after intraperitoneal injections of saline or salicylate $(300 \mathrm{mg} / \mathrm{kg})$. $B$ represents the number of abnormal jumps during silent periods (false positives). The score remained stable ( $\sim 90 \%$ ) during the time course of the experiment for the saline group (filled circles; $n=10$ ), even during the intraperitoneal injections of saline. Note the absence of false positive responses (i.e., animals did not execute the task during silent periods). Injections of salicylate (open circles; $n=$ 10 ) reduced the score ( $p<0.05$ at days 3 and 4 ) and significantly $(p<0.001)$ increased the number of false positives as soon as the first day of treatment. A complete recovery was seen when the treatment was stopped. Note the different time pattern of change induced by salicylate on the score and the false positives.

day 8). Salicylate treatment provoked a drastic increase of false positive responses. The first significant $(p<0.001)$ increase was observed $2 \mathrm{hr}$ after the first injection of salicylate $[0.3 \pm 0.15$ false response before treatment (day 0 ) vs $1.6 \pm 0.16$ after the first day of treatment (day 1)]. In contrast to the score, no plateau was observed, and false positive responses increased monotonically during the time course of the treatment to reach a maximum $(6.0 \pm 1.09$ false positive responses) by the last day of the treatment (day 4). The time course of the recovery was slower than that of the score. Whereas scores returned to normal value in $1 \mathrm{~d}$, false positive responses needed $3 \mathrm{~d}$ to recover from salicylate treatment (day 8$)$.

It has been proposed that salicylate induced tinnitus at a frequency of $\sim 10 \mathrm{kHz}$ in rats (Jastreboff et al., 1988). To determine whether the present behavioral changes were linked to tinnitus, we performed additional experiments to test what happens if the 

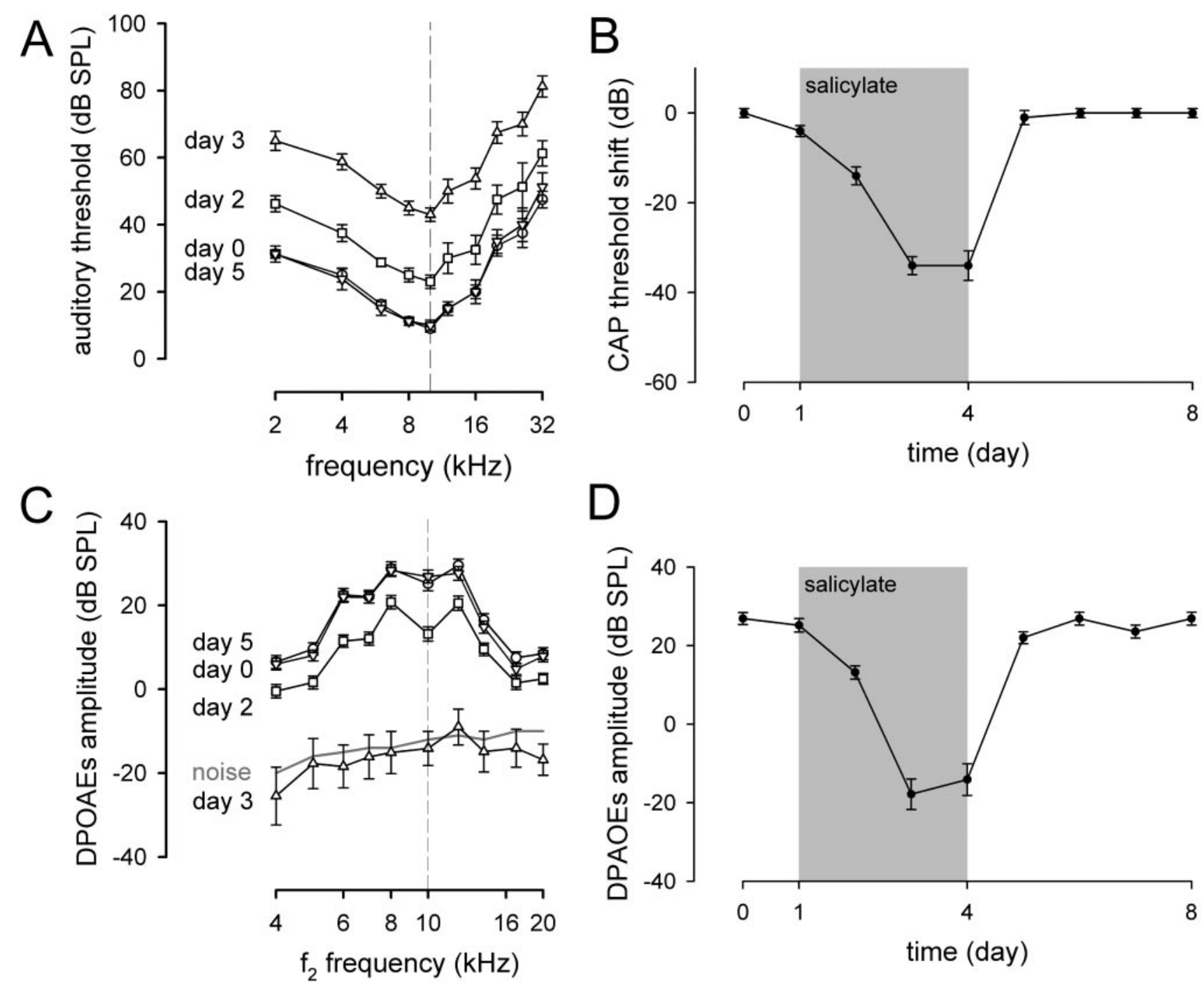

Figure 3. CAP and DPOAE measurements. Hearing loss induced by salicylate was assessed by recording CAP and DPOAE measurements. $A$, Shown are the CAP audiograms for animals $(n=6)$ before salicylate treatment (day 0; circles), after the second injection of salicylate (day 2; squares), after the third injection of salicylate (day 3; upward triangles), and the first day of recovery (day 5; inverted triangles). The broken line represents $10 \mathrm{kHz}$. B, CAP threshold shift for $10 \mathrm{kHz}$ before, during, and after salicylate treatment (gray area). CAP threshold shifts at $10 \mathrm{kHz}$ were calculated as the difference in decibels between the auditory threshold recorded at day 0 and those recorded on following days. $C$, Shown are the DPOAE amplitudes as a function of $f_{2}$ frequency for animals $(n=$ 6) before salicylate treatment (day 0; circles), after the second injection of salicylate (day 2; squares), after the third injection of salicylate (day 3; upward triangles), and the first day of recovery (day 5 ; inverted triangles). The broken line represents $10 \mathrm{kHz}$. After the third injection of salicylate (day 3), DPOAEs disappeared into the noise floor. A complete recovery to pretreatment amplitudes was seen $1 \mathrm{~d}$ after the end of salicylate treatment. $D$, Changes in DPOAE amplitudes for $f_{2}=10 \mathrm{kHz}$ before, during, and after salicylate treatment (gray area). Note the similarity of the time course of hearing loss assessed by CAP and DPOAE measurements and the reduction of the score shown in Fig. 2A. The first significant change in CAP and DPOAE was observed at day 2 ( $p<0.001$ ).

animal was conditioned with a tone that does not "sound" like tinnitus. When animals were conditioned with a $4 \mathrm{kHz}$ tone $(n=$ 10) rather than $10 \mathrm{kHz}$, salicylate treatment reduced the score $(84.0 \pm 1.63$ and $72.0 \pm 2 \%$ at days 0 and 4 , respectively) but failed to increase the false positive responses $[0.2 \pm 0.13$ false response before treatment (day 0 ) vs $0.3 \pm 0.15$ at the end of the treatment (day 4)].

\section{Relationship between hearing and behavioral score}

To investigate whether the decrease of the score was linked to the occurrence of hearing loss attributable to salicylate treatment, we monitored auditory function by recording CAP and DPOAE audiograms.

CAP of the auditory nerve

Cumulative injections of salicylate induced a parallel shift of CAP thresholds from 2 to $32 \mathrm{kHz}$ (Fig. $3 A$ ). A full recovery to the pretreatment value was observed $1 \mathrm{~d}$ after the treatment had stopped (day 5). CAP threshold shifts were calculated at $10 \mathrm{kHz}$ as the difference in decibels between the auditory threshold before and during treatment (Fig. 3B). As seen for the score, the CAP threshold shift reached a plateau on the third $(p<0.001)$ and fourth $(p<0.001)$ days of treatment $(34.0 \pm 2.0$ and $34.0 \pm 3.31$ $\mathrm{dB}$ at days 3 and 4 , respectively) and recovered at the end of the treatment.

\section{DPOAES}

The high degree of sensitivity and frequency selectivity of the cochlea is attributable to active mechanisms generated by outer hair cells (Brownell et al., 1985). These active mechanisms induce a nonlinearity of the cochlea that can be easily recorded by a sensitive microphone placed into the ear canal as DPOAEs (Kemp, 1978). In the present experiment, cumulative injections of salicylate decreased the amplitude of DPOAEs (Fig. 3C,D). 


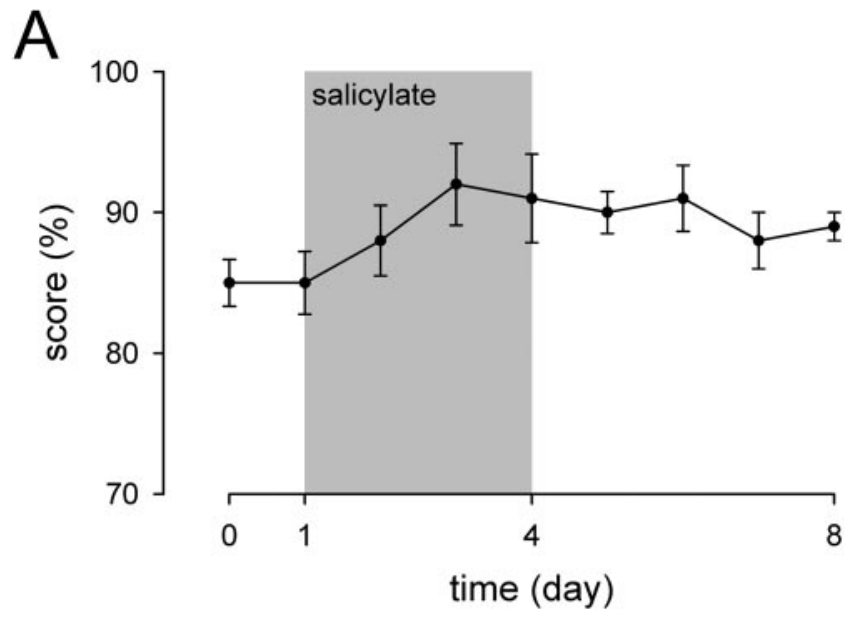

B

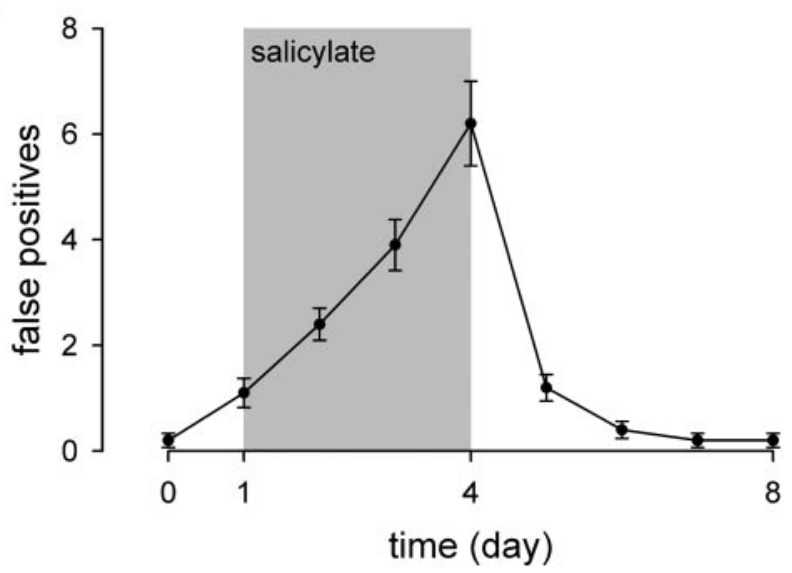

Figure 4. Measurement of score and false positive responses at constant perceptive level. Hearing loss induced by salicylate was compensated by adjusting the intensity of sound eliciting behavioral responses as a function of threshold shift (gray area; $n=10$ ). $A$, A slight, but not significant ( $p=0.287$ ), increase of the score was observed in animals in which sound was presented at constant perceptive level. $B$, Presentation of sound at a constant perceptive level did not affect the increase of false positive responses induced by salicylate treatment, the first significant increase being observed at day $1(p<0.001)$.

This decrease led to a complete disappearance into the noise floor the third and the fourth days of treatment. A full recovery to pretreatment values was observed $1 \mathrm{~d}$ after the end of salicylate injections (day 5). Together with the CAP threshold shift, the reduction of the DPOAE amplitude showed that salicylate acts on OHCs.

Salicylate treatment in constant perceptive level

Worthy of note is the similarity in the time course of the reduction of score and those of CAP threshold and DPOAE amplitude, suggesting that the decrease of the score is related to the occurrence of hearing loss. To test this hypothesis, the intensity of sound eliciting behavioral responses was adjusted as a function of CAP threshold elevation to provide a constant perceptive level of the sound. In such conditions, no significant decrease, but a slight, not significant ( $p=0.287)$ increase in the score was observed (Fig. 4A). However, the increase in the number of false positive responses still remained (Fig. $4 B$ ), the maximum value being comparable with those measured in noncompensated salicylate-treated animals $(6.0 \pm 1.09$ false positive responses vs $6.20 \pm 0.80$ in noncompensated and compensated animals, respectively). For example, the best responding animal (score of
A

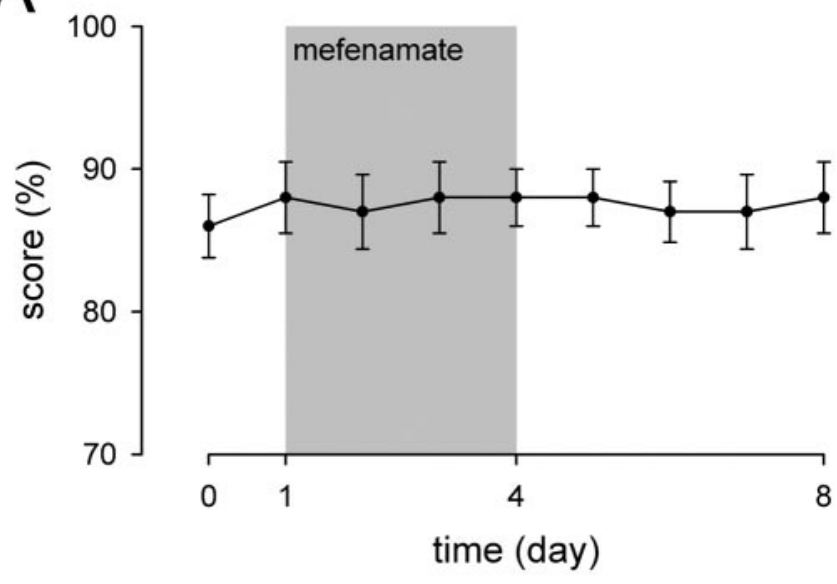

B

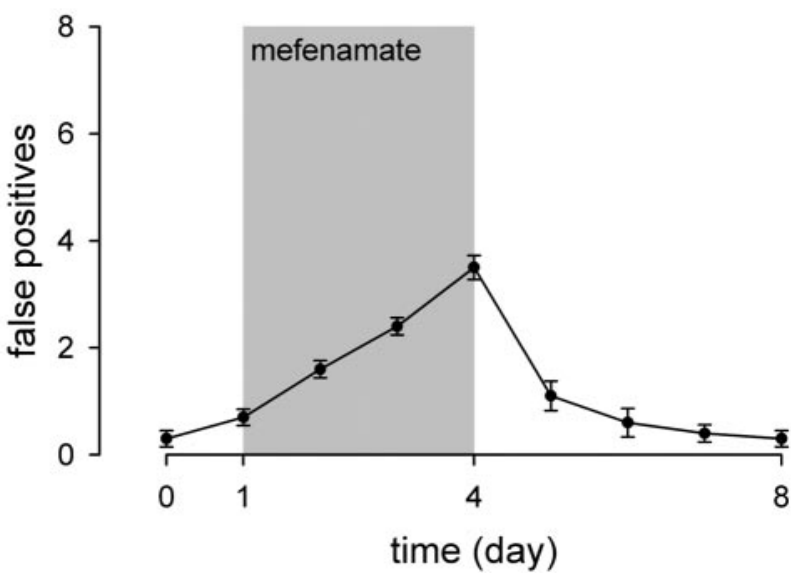

Figure 5. Measurement of the score and false positive responses in mefenamate-treated animals. To determine whether changes of behavioral responses induced by salicylate were linked to cyclooxygenase inhibition, we investigated the effect of intraperitoneal injection of mefenamate. The mefenamate treatment ( $35 \mathrm{mg} / \mathrm{kg}$ ) lasted $4 \mathrm{~d}$ (from day 1 to day 4 ; gray area). $A$ represents the percentage of correct responses to sound (score). $B$ represents the number of abnormal jumping during silent periods (false positives). Whereas mefenamate did not significantly change the score, it did significantly increase in the number of false positive responses $(n=10)$, the first significant increase being observed at day $2(p<0.001)$.

$100 \%$ ) showed 12 false positives on the fourth day of salicylate treatment, whereas the worst (score of $80 \%$ ) displayed four false positives. As seen in noncompensated animals, a recovery also required $3 \mathrm{~d}$ to return to pretreatment values.

\section{Mechanism of salicylate-induced false positive responses}

False positive increase is linked to cyclooxygenase inhibition

To determine whether changes of behavioral responses induced by salicylate was linked to cyclooxygenase inhibition, we investigated the effect of mefenamate (a potent cyclooxygenase inhibitor). In contrast to salicylate, cumulative intraperitoneal injections of $35 \mathrm{mg} / \mathrm{kg}$ mefenamate did not affect the score of animals (Fig. 5A). As seen for salicylate, this treatment led to a lesser, but significant, increase $(p<0.001)$ in the number of false positive responses $(3.5 \pm 0.22$ false positive responses vs $6.0 \pm 1.09$ after $4 \mathrm{~d}$ of treatment with mefenamate and salicylate, respectively). False positive responses returned to pretreatment values within $3 \mathrm{~d}$ (Fig. 5B). This suggests that the change in false positive responses, but not the score, is attributable to the inhibition of the cyclooxygenase pathway. 
A
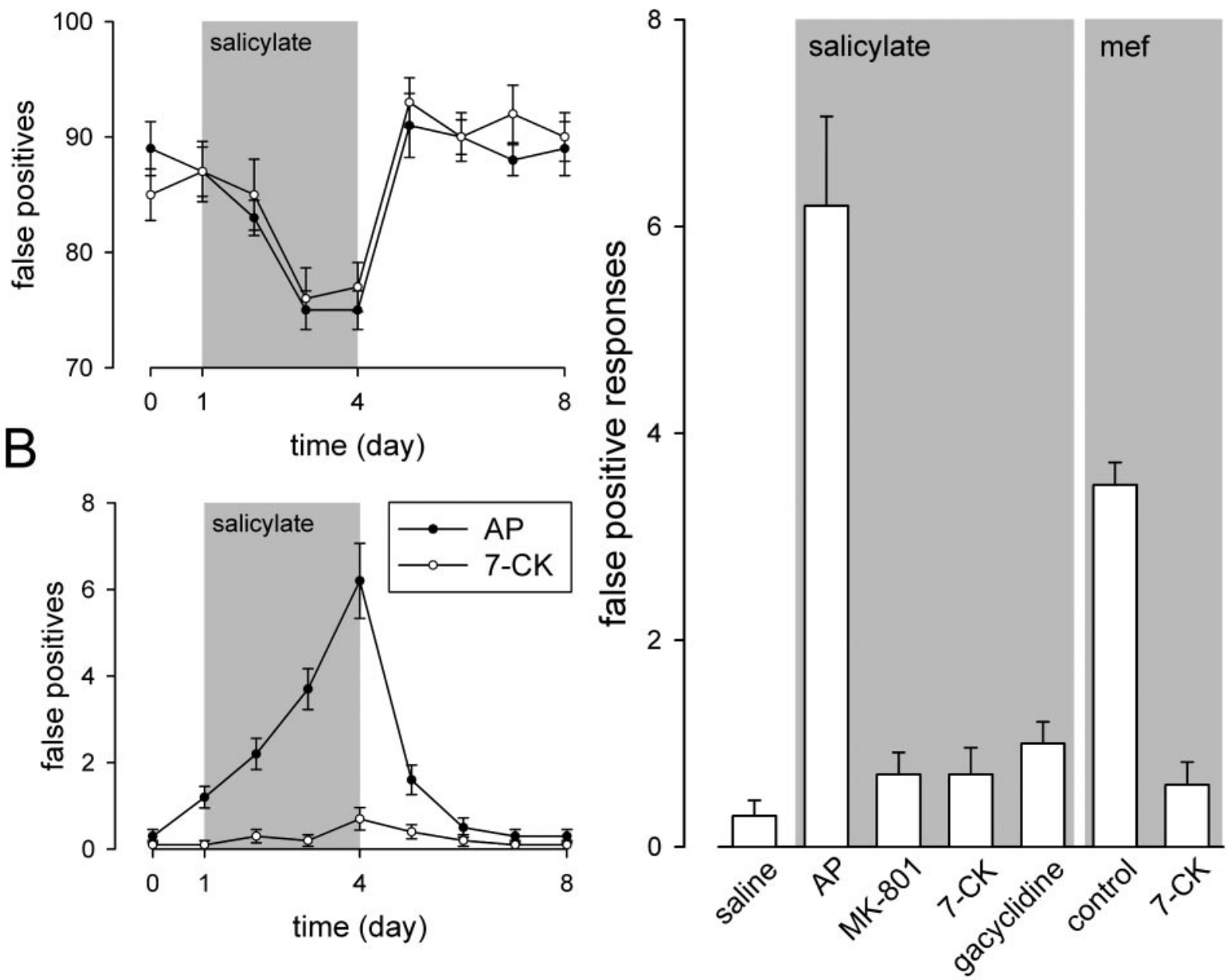

Figure 6. Score and false positive responses after cochlear NMDA receptor blockade. NMDA antagonists were applied into the perilymphatic fluids using Gelfoam placed on the round window of both ears. Surgery to place Gelfoam on the round window was done immediately after the first behavioral measurement (day 0$)$. $A$, Gelfoam bathed with control artificial perilymph alone (AP; $n=$ 10; filled circles) or containing $50 \mu \mathrm{m} 7$-CK ( $n=10$; open circles) did not change the degree and the time course of the reduction of the score. $B$, In contrast, application of 7-CK into the perilymphatic fluids significantly reduced the number of false positive responses. C, Shown are the number of false positive responses measured at day 4 in animals injected with saline solution (saline) and in animals injected with salicylate plus Gelfoam bathed with artificial perilymph alone (AP; $n=10$ ) or MK-801 (10 $\mu \mathrm{m} ; n=10), 7-\mathrm{CK}(50 \mu \mathrm{m} ; n=10)$, or gacyclidine (50 $\mu \mathrm{m} ; n=10)$. When compared with artificial perilymph alone, local application of MK-801, 7-CK, or gacyclidine significantly $(p<0.001)$ reduced the occurrence of the false positive responses. When compared with animals injected with mefenamate alone (control), application of Gelfoam containing $50 \mu \mathrm{m}$ 7-CK significantly reduced the occurrence of the false positive responses.

Salicylate induced false positives via cochlear NMDA receptors To test the hypothesis that salicylate and mefenamate induced false positives via cochlear NMDA receptors, we applied NMDA antagonists into the perilymphatic fluids using Gelfoam placed on the round window of both ears. Local application of control artificial perilymph did not influence the decrease of the score (Fig. 6A) or the increase of the number of false positive responses induced by salicylate (Fig. $6 \mathrm{~B}$ ). In contrast, local application of 10 $\mu \mathrm{M} \mathrm{MK}-801,50 \mu \mathrm{M}$ 7-CK, or $50 \mu \mathrm{M}$ gacyclidine strongly reduced the occurrence of false positive responses induced by salicylate but did not affect the reduction of the score (Fig. 6A,B). When compared with the control artificial perilymph animals at day 4 (6.2 \pm 0.86 false positives), the number of false positive responses fell to $0.7 \pm 0.21,0.7 \pm 0.26$, and $1 \pm 0.21$ for MK-801, 7-CK, and gacyclidine, respectively (Fig. $5 C$ ). In addition, $7-\mathrm{CK}$ also blocked the number of false positive responses in mefenamate-treated animals $(3.5 \pm 0.22$ false positive responses vs $0.6 \pm 0.22$ after $4 \mathrm{~d}$ in control and 7-CK animals, respectively) (Fig. 6C). The lack of change in the score further suggests that local application of NMDA antagonists does not produce nonspecific effects such as locomotor impairment.

\section{Discussion}

In the present study, we developed a new behavioral procedure to assess the occurrence of tinnitus in animals. This behavioral model of tinnitus allowed us to demonstrate that inhibition of cyclooxygenase is one of the mechanisms responsible for the generation of tinnitus induced by salicylate via the activation of cochlear NMDA receptors.

\section{Behavioral model of salicylate-induced tinnitus in rats}

The first behavioral model of tinnitus developed in rats by Jastreboff and colleagues used salicylate, which is known to induce tinnitus in humans (McCabe and Dey, 1965; Myers and Bernstein, 1965). The protocol was a conditioned suppression paradigm on the basis of water deprivation (Jastreboff et al., 1988; 
Jastreboff and Sasaki, 1994). Briefly, animals were trained to stop drinking whenever the broadband noise was turned off by pairing its absence with footshocks. Rats treated with salicylate were less likely than control animals to stop drinking when the noise was turned off. This result has been taken to indicate that animals treated with salicylate could still hear when no external sound was present, i.e., they had tinnitus. Using this procedure, the pitch of salicylate-induced tinnitus in rats was also assessed. Results indicated that 10 and $11 \mathrm{kHz}$ had the strongest effect, which is consistent with human reports of high-pitch tinnitus induced by salicylate. Consistently, we report that salicylate failed to increase the false positive responses in animals conditioned with a tone that does not "sound" like tinnitus (i.e., $4 \mathrm{kHz}$ tone rather than 10 $\mathrm{kHz})$.

One major feature of Jastreboff's protocol, however, is that animals have to be kept thirsty, leading to a loss of body weight up to $20 \%$. The present study required surgery to apply drugs on the round window, which is not compatible with alterations of physiological state such as a loss of body weight. Because of this limitation, we designed a new behavioral model based on an active avoidance paradigm. To match salicylate-induced tinnitus in rats, conditioning was performed with a sound of $10 \mathrm{kHz}$ (Jastreboff and Sasaki, 1994). Administering salicylate led to a progressive decrease in the score and a concomitant development of hearing loss, as demonstrated by CAP threshold recordings. When the intensity of sound eliciting behavioral responses was adjusted as a function of CAP threshold shift, no significant decrease in the score was observed. Together with the striking similarity between time pattern of CAP threshold shifts, DPOAEs recordings, and score measurements, these results reveal that the decrease in score was linked to salicylate-induced hearing loss. Consequently, measurement of the score may constitute a good behavioral indicator of hearing performance.

Salicylate-treated animals are expected to have tinnitus (Jastreboff et al., 1988; Jastreboff and Sasaki, 1994; Bauer et al., 1999). Because they have a sound hallucination (i.e., tinnitus), they are more likely to execute the motor task during the silent periods. If true, animals treated with salicylate will increase their false positive responses, i.e., they would behave as if they hear a sound when no external sound is presented. Our results demonstrate that animals treated with salicylate significantly increase the number of false positive responses (they jump to the climbing pole) during silent periods. A key question is whether this result is attributable to tinnitus or other factors. An alternative explanation is that the salicylate-treated animals respond differently because of hearing loss. Indeed, CAP threshold recordings attested that the salicylate treatment used in this study induced hearing loss. For this reason, the animals that did not correctly hear the conditioning stimulus reduced the number of correct responses to sound (i.e., score). Consequently, the number of footshocks increased. This may thus result in the development of an escape behavior, leading to the increase of false positive responses. However, the presence of false positive responses when the external sound is presented at constant perceptive level is the most convincing evidence that false positive responses are not linked to hearing loss. Thus, hearing loss cannot account for the increase of false positive responses. Another possibility could be that salicylate-induced false positives is related to hyperactivity. The fact that mefenamate also induced an increase of false positives and that other cyclooxygenase inhibitors inhibited (Herman et al., 1987) or did not change locomotor activity (Jain et al., 2002; Ross et al., 2002) does not support this hypothesis. An alternative explanation may be the introduction of a stressor such as the nociceptive stimulus attributable to the needle contact or the injection itself. This possibility can also be ruled out because saline injections did not induce false positive responses.

\section{Origin of salicylate-induced tinnitus}

The site of generation of tinnitus is a key issue to understand mechanisms of the symptoms and the efficiency of potential treatment. Together with others (McFadden and Plattsmier, 1984; Long and Tubis, 1988; Kujawa et al., 1994), we reported a salicylate-induced abolishment of DPOAEs. This confirms that salicylate-induced hearing loss is attributable to an action on OHCs (Zheng et al., 2000; Oliver et al., 2001; Zhang et al., 2001). In addition, salicylate has been reported to increase the spontaneous activity of the auditory nerve (Evans et al., 1981; Evans and Borerwe, 1982; Stypulkowski, 1990) and to change the average spectrum of cochleoneural activity (Schreiner and Snyder, 1987; Martin et al., 1993; Cazals et al., 1998). Increased spontaneous activity also occurred in the inferior colliculus (Jastreboff and Sasaki, 1986; Chen and Jastreboff 1995; Manabe et al., 1997) and the auditory cortex (Ochi and Eggermont, 1996). Cells recorded from nonauditory structures physically adjacent to the inferior colliculus (lobulus $\mathrm{V}$ of the cerebellar vermis) showed no change in spontaneous activity (Jastreboff and Sasaki, 1986). The selectivity of salicylate influencing auditory pathways argues against the nonspecific action of salicylate on the nervous system. This supports the view that abnormal activities are specifically propagated within the auditory system, and these abnormalities may be erroneously interpreted as sound by higher auditory centers.

\section{Mechanisms of action of salicylate}

The most known pharmacological effect of salicylate is the inhibition of cyclooxygenase activity (Vane, 1971; Mitchell et al., 1993; Vane and Botting, 1998). To determine whether changes in behavioral responses induced by salicylate were linked to cyclooxygenase inhibition, we investigated the effect of mefenamate, another potent cyclooxygenase inhibitor. In the present study, daily intraperitoneal injections of mefenamate did not change the score of animals. If the score is an indicator of hearing loss (as discussed above), one may expect that mefenamate will not change auditory threshold. Consistently, Puel et al. (1990) showed that intracochlear perfusions of two cyclooxygenase inhibitors, mefenate and meclofenamate, had no effect on cochlear potentials. In the present study, mefenamate treatment significantly increases the number of false positive responses, attesting to the independence between false positive responses and hearing loss. Thus, inhibition of the cyclooxygenase pathway is one of the mechanisms by which salicylate and mefenamate induce an increase of false positive responses. Interestingly, it is the difference between the time course for the induction and extinction of hearing loss and false positive responses. In contrast to the relatively rapid, reversible decrease in hearing sensitivity and otoacoustic emissions that are associated with salicylate toxicity, the present study shows that the false positive effect builds over days and requires days to extinguish. This leads to the proposal that abnormal behavior related to tinnitus may have identified another signature of salicylate action. In other systems, irreversible acetylation of cyclooxygenases by salicylate blocks the conversion of arachidonic acid to prostanoids, and the recovery from salicylate reflects the turnover of these enzymes (Amann and Peskar, 2002). The $3 \mathrm{~d}$ extinction time for false positive responses may thus reflect the turnover time for expression of the enzymes.

One physiological basis of salicylate ototoxicity is likely to originate from altered arachidonic acid metabolism (Escoubet et 
al., 1985; Jung et al., 1993, Cazals, 2000). Electrophysiological studies have demonstrated that arachidonic acid increases the channel opening probability of NMDA receptor in various systems, including cerebellar granule cells, dissociated pyramidal cells, cortical neurons, and adult hippocampal slices (Miller et al., 1992; Horimoto et al., 1996; Yamakura and Shimoji, 1999). The potentiation of NMDA responses by arachidonic acid is observed in both native and recombinant receptors (Casado and Ascher, 1998) and occurs even with saturating levels of agonists at the glutamate- and glycine-binding sites (Miller et al., 1992). In the cochlea, the normal synaptic transmission between inner ear cells and primary auditory neurons is mediated by AMPA receptors (Ruel et al., 1999, 2000). However, analysis of gene expression, immunocytochemistry, and in situ hybridization indicates that the cochlea express NR1 and NR2A-NR2D subunits of NMDA receptors (Niedzielski and Wenthold, 1995; Usami et al., 1995). Although these NMDA receptors are not involved in cochlear synaptic transmission, they are implicated in synaptic repair after excitotoxicity (d'Aldin et al., 1997), and NMDA antagonists protect sensory hair cells from aminoglycoside ototoxicity (Basile et al., 1996) and prevent excitotoxicity induced by cochlear ischemia and acoustic trauma (Puel et al., 1994; Puel, 1995; Duan et al., 2000). We therefore tested the hypothesis that salicylate and mefenamate induce false positives through activation of cochlear NMDA receptors. When applied into the perilymphatic fluids of the cochleas, the NMDA antagonists MK-801 (channel blocker), 7-chlorokynurenate (glycine-site antagonist), and gacyclidine (phencyclidine-site antagonist) strongly reduced the occurrence of false positive responses induced by salicylate or mefenamate. Although direct explanation on the molecular mechanisms of salicylate and mefenamate action on cochlear NMDA receptors have to be determined, the present study supports the implication of cochlear NMDA receptors in the generation of salicylateinduced tinnitus through a mechanism involving the cyclooxygenase pathway. In contrast, the three NMDA antagonists did not prevent salicylate-induced reduction of the score. Together, results attest that salicylate has two different sites of action within the cochlea: the first one is on the molecular motor of OHCs accounting for hearing loss, the second one on NMDA receptors accounting for the generation of tinnitus.

In conclusion, the present study provides evidence for a new pharmacological effect of salicylate in inner ear physiology. In addition to reducing OHCs electromotility, salicylate may act on cochlear fast synaptic transmission via the activation of NMDA receptors, accounting for the occurrence of tinnitus. Additional experiments are needed to confirm the implication of cochlear NMDA receptors in other models of tinnitus such as noise trauma, ischemia, aminoglycosides, or cisplatin ototoxicity. NMDA antagonists may thus constitute an attractive candidate for the treatment of tinnitus in humans (Pujol, 1992; Puel, 1995; Simpson and Davies, 1999).

\section{References}

Amann R, Peskar BA (2002) Anti-inflammatory effects of aspirin and sodium salicyalte. Eur J Pharmacol 447:1-9.

Basile AS, Huang JM, Xie C, Webster D, Berlin C, Skolnick P (1996) $\mathrm{N}$-methyl-D-aspartate antagonists limit aminoglycoside antibioticinduced hearing loss. Nat Med 2:1338-1343.

Bauer CA, Brozoski TJ, Rojas R, Boley J, Wyder M (1999) Behavioral model of chronic tinnitus in rats. Otolaryngol Head Neck Surg 121:457-462.

Brownell WE, Bader CR, Bertrand D, de Ribaupierre Y (1985) Evoked mechanical responses of isolated cochlear outer hair cells. Science 227:194-196.
Casado M, Ascher P (1998) Opposite modulation of NMDA receptors by lysophospolipids and arachidonic acid: common features with mechanosensitivity. J Physiol (Lond) 513:317-330.

Cazals Y (2000) Auditory sensori-neural alterations induced by salicylate. Prog Neurobiol 62:583-631.

Cazals Y, Horner KC, Huang ZW (1998) Alterations in average spectrum of cochleoneural activity by long-term salicylate treatment in the guinea pig: a plausible index of tinnitus. J Neurophysiol 80:2113-2120.

Chen G, Jastreboff PJ (1995) Salicylate-induced abnormal activity in the inferior colliculus of rats. Hear Res 82:158-178.

d'Aldin CG, Ruel J, Assie R, Pujol R, Puel JL (1997) Implication of NMDA type glutamate receptors in neural regeneration and neoformation of synapses after excitotoxic injury in the guinea pig cochlea. Int J Dev Neurosci 15:619-629.

Duan M, Agerman K, Ernfirs P, Canlon B (2000) Complementary roles of neurotrophin 3 and a $N$-methyl-D-aspartate antagonist in the protection of noise and aminoglycoside-induced ototoxicity. Proc Natl Acad Sci USA 97:7597-7602.

Escoubet B, Amsallem P, Ferrary E, Tran Ba Huy P (1985) Prostaglandin synthesis by the cochlea of the guinea pig. Influence of aspirin, gentamicin, and acoustic stimulation. Prostaglandins 29:589-599.

Evans EF, Borerwe TA (1982) Ototoxic effects of salcylates on the responses of single cochlear nerve fibers and on cochlear potentials. Br J Audiol 16:101-108.

Evans EF, Wilson JP, Borerwe TA (1981) Animal models of tinnitus. In: Tinnitus, Ciba Foundation Symposium 85, pp 108-138. London: Pitman.

Glowatzki E, Fuchs PA (2002) Transmitter release at the hair cell ribbon synapse. Nat Neurosci 5:147-154.

Herman ZS, Brus R, Sokola A, Szkilnik R, Kmieciak-Kolada K, Zielinski M, Standa J, Trzeciak HI (1987) Basic pharmacological properties of a novel antiinflammatory drug tryptamide. Pol J Pharmacol Pharm 39:729-736.

Horimoto N, Nabekura J, Ogawa T (1996) Developmental changes in arachidonic acid potentiation of NMDA currents in cortical neurones. NeuroReport 7:2463-2467.

Jain NK, Patil CS, Kulkarni SK, Singh A (2002) Modulatory role of cyclooxygenase inhibitors in aging- and scopolamine or lipopolysaccharideinduced cognitive dysfunction in mice. Behav Brain Res 133:369-376.

Jastreboff PJ, Sasaki CT (1986) Salicylate-induced changes in spontaneous activity of single units in the inferior colliculus of the guinea pig. J Acoust Soc Am 80:1384-1391.

Jastreboff PJ, Sasaki CT (1994) An animal model of tinnitus: a decade of development. Am J Otol 15:19-27.

Jastreboff PJ, Brennan JF, Coleman JK, Sasaki CT (1988) Phantom auditory sensation in rats: an animal model for tinnitus. Behav Neurosci 102:811-822.

Jung TT, Rhee CK, Lee CS, Park YS, Choi DC (1993) Ototoxicity of salicylate, nonsteroidal antiinflammatory drugs, and quinine. Otolaryngol Clin North Am 26:791-810.

Kakehata S, Santos-Sacchi J (1996) Effects of salicylate and lanthanides on outer hair cell motility and associated gating charge. J Neurosci 16:4881-4889.

Kemp DT (1978) Stimulated acoustic emissions from within the human auditory system. J Acoust Soc Am 64:1386-1391.

Kujawa SG, Glattke TJ, Fallon M, Bobbin RP (1994) A nicotinic-like receptor mediates suppression of distortion product otoacoustic emissions by contralateral sound. Hear Res 74:122-134.

Long GR, Tubis A (1988) Modification of spontaneous and evoked otoacoustic emissions and associated psychoacoustic microstructure by aspirin consumption. J Acoust Soc Am 84:1343-1353.

Manabe Y, Yoshida S, Saito H, Oka H (1997) Effects of lidocaine on salicylate-induced discharge of neurons in the inferior colliculus of the guinea pig. Hear Res 103:192-198.

Martin WH, Schwegler JW, Scheibelhoffer J, Ronis ML (1993) Salicylateinduced changes in cat auditory nerve activity. Laryngoscope 103:600-604.

McCabe PA, Dey FL (1965) The effect of aspirin upon auditory sensitivity. Ann Otol Rhinol Laryngol 74:312-324.

McFadden D, Plattsmier HS (1984) Aspirin abolishes spontaneous otoacoustic emissions. J Acoust Soc Am 76:443-448.

Miller B, Sarantis M, Traynelis SF, Attwell D (1992) Potentiation of NMDA receptor currents by arachidonic acid. Nature 355:722-725 
Mitchell JA, Akarasereenont P, Thiemermann C, Flower RJ, Vane JR (1993) Selectivity of nonsteroidal antiinflammatory drugs as inhibitors of constitutive and inducible cyclooxygenase. Proc Natl Acad Sci USA 90:11693-11697.

Myers E, Bernstein JM (1965) Salicylate ototoxicity a clinical and experimental study. Arch Otolaryngol 82:483-493.

Niedzielski AS, Wenthold RJ (1995) Expression of AMPA, kainate, and NMDA receptor subunits in cochlear and vestibular ganglia. J Neurosci 15:2338-2353.

Ochi K, Eggermont JJ (1996) Effects of salicylate on neural activity in cat primary auditory cortex. Hear Res 95:63-76.

Oliver D, He DZ, Klocker N, Ludwig J, Schulte U, Waldegger S, Ruppersberg JP, Dallos P, Fakler B (2001) Intracellular anions as the voltage sensor of prestin, the outer hair cell motor protein. Science 292:2340-2343.

Puel JL (1995) Chemical synaptic transmission in the cochlea. Prog Neurobiol 47:449-476.

Puel JL, Bobbin RP, Fallon M (1990) Salicylate, mefenamate, meclofenamate, and quinine on cochlear potentials. Otolaryngol Head Neck Surg 102:66-73.

Puel JL, Pujol R, Tribillac F, Ladrech S, Eybalin M (1994) Excitatory amino acid antagonists protect cochlear auditory neurons from excitotoxicity. J Comp Neurol 341:241-256.

Puel JL, Durrieu JP, Rebillard G, Vidal D, Assié R, Uziel A (1995) Comparison between auditory brainstem responses and distorsion produces otoacoustic emissions after temporary threshold shift in guinea-pig. Acta Acustica 3:75-82.

Pujol R (1992) Neuropharmacology of the cochlea and tinnitus. In: Tinnitus 91 (Aran J-M, Dauman R, eds), pp 103-107. New York: Kugler.

Ross BM, Brooks RJ, Lee M, Kalasinsky KS, Vorce SP, Seeman M, Fletcher PJ, Turenne SD (2002) Cyclooxygenase inhibitor modulation of dopaminerelated behaviours. Eur J Pharmacol 450:141-151.

Ruel J, Chen C, Pujol R, Bobbin RP, Puel JL (1999) Ampa-preferring glutamate receptors in cochlear physiology of adult guinea pig. J Physiol (Lond) 518:667-680.
Ruel J, Bobbin RP, Vidal D, Pujol R, Puel JL (2000) The selective AMPA receptor antagonist GYKI 53784 blocks action potential generation and excitotoxicity in the guinea pig cochlea. Neuropharmacology 39:1959-1973.

Schreiner CE, Snyder RL (1987) A physiological animal model of peripheral tinnitus. In: Proceedings of the 3rd International Tinnitus Seminar (Feldmann H, ed), pp 100-106. Karlsruhe, Germany: Verlag.

Sée G (1877) Etudes sur l'acide salicylique et les salicylates; traitement du rhumatisme aigu et chronique et de la goutte, et de diverses affections du système nerveux sensitif par les salicylates. Bull Acad Natl Med 26:689-706.

Simpson JJ, Davies WE (1999) Recent advances in the pharmacological treatment of tinnitus. Trends Pharmacol 20:12-18.

Stypulkowski PH (1990) Mechanisms of salicylate ototoxicity. Hear Res 46:113-146.

Thiemermann C (1991) Biosynthesis and interaction of endotheliumderived vasoactive mediators. Eicosanoids 4:187-202.

Usami S, Matsubara A, Fujita S, Shinkawa H, Hayashi M (1995) NMDA (NMDAR1) and AMPA-type (GluR2/3) receptor subunits are expressed in the inner ear. NeuroReport 6:1161-1164.

Vane JR (1971) Inhibition of prostaglandin synthesis as a mechanism of action for aspirin-like drugs. Nature 231:232-235.

Vane JR, Botting RM (1998) Mechanism of action of nonsteroidal antiinflammatory drugs. Am J Med 104:2S-8S.

Vane JR, Bakhle YS, Botting RM (1998) Cyclooxygenases 1 and 2. Annu Rev Pharmacol Toxicol 38:97-120.

Yamakura T, Shimoji K (1999) Subunit- and site-specific pharmacology of the NMDA receptor channel. Prog Neurobiol 59:279-298.

Zhang PC, Keleshian AM, Sachs F (2001) Voltage-induced membrane movement. Nature 413:428-432.

Zheng J, Shen W, He DZ, Long KB, Madison LD, Dallos P (2000) Prestin is the motor protein of cochlear outer hair cells. Nature 405:149-155. 